\title{
Aproveitamento integral de alimentos: desenvolvimento de bolos de banana destinados à alimentação escolar
}

\author{
Laila Santos VIEIRA ${ }^{1}$ \\ Camilla Ribeiro VIEIRA ${ }^{1}$ \\ Tatiane FARIA ${ }^{1}$ \\ Eveline Monteiro Cordeiro de AZEREDO ${ }^{2}$ \\ ${ }^{1}$ Graduandas em Nutrição pela Universidade Federal de Alfenas (UNIFAL-MG). E-mail: laila.nutri@ yahoo.com.br \\ ${ }^{2}$ Nutricionista, Professora da UNIFAL-MG, Departamento de Nutrição
}

Recebido em: 30/05/2013 - Aprovado em: 15/07/2013 - Disponibilizado em: 15/08/2013

\section{RESUMO}

A escola exerce grande influência na formação dos hábitos alimentares de crianças e adolescentes, sendo este público essencial para a multiplicação de informações. O aproveitamento de partes de alimentos que, normalmente são desprezadas, além de tornar a preparação de baixo custo, ser de fácil acesso e melhorar o valor nutricional, proporciona o aumento do rendimento da refeição. A utilização de resíduos de frutas, aliada ao desenvolvimento de tecnologias para minimizar as perdas nos processos produtivos, podem contribuir de forma relevante para a economia do país e a diminuição dos impactos ambientais. Assim, este trabalho teve como objetivo desenvolver bolo de banana destinado à alimentação escolar. Foram desenvolvidos dois tipos de preparações: uma com a fruta íntegra (incluindo a casca), e outra contendo somente o fruto. Realizaram-se análises físico-químicas dos bolos, determinando-se umidade, textura, teor proteínas, carboidratos e lipídeos. Os resultados não revelaram diferença estatística significativa na composição centesimal dos mesmos. A análise sensorial realizada com crianças entre nove e 11 anos de uma escola pública do município de Alfenas, MG, também não revelou preferência expressiva. Os resultados demonstram a importância do desenvolvimento de preparações alimentícias que utilizem o alimento de forma integral e sua inclusão na alimentação escolar, de forma a contribuir ao acesso a uma alimentação saudável e de baixo custo.

Palavras-chave: Alimentação Escolar. Bolos. Desperdício. Banana. Aproveitamento Integral

\section{Full use of food: the development of banana cakes intended for school}

\begin{abstract}
The school has great influence in shaping the eating habits of children and adolescents, which is essential for the multiplication public information. The use of parts of food that are usually discarded, besides making the preparation of low-cost, easily accessible and improve the nutritional value, provides the increased performance of the meal. The use of waste fruit, coupled with the development of technologies to minimize losses in production processes, may contribute significantly to the countries economy and reducing environmental impacts. This study aimed to develop banana cake for the school feeding. Were developed two types of preparation: with one full fruit (including the peel) and one containing only the fruit. Analyses physicochemical cakes, determining moisture, texture, protein content, carbohydrates and lipids. The results revealed no statistically significant differences in the chemical composition thereof. Sensory analysis conducted with children between nine and 11 years in a public school in Alfenas city, MG, also revealed no significant preference. The results demonstrate the importance of developing food preparations using the integral form of food and its inclusion in school meals, in order to contribute to access to healthy food and low cost.
\end{abstract}

Keywords: School Meals. Cakes. Waste. Banana. Harnessing utilization 


\section{INTRODUÇÃO}

O ambiente escolar exerce grande influência na formação de crianças e adolescentes, atores da comunidade escolar essenciais para a multiplicação de informações. Constitui um centro de ensinoaprendizagem, convivência e crescimento importante e nela se adquirem valores vitais fundamentais (BRASIL, 2011). É, portanto, espaço de grande relevância para a promoção da saúde, principalmente quando esta questão se insere na constituição do conhecimento do cidadão crítico, estimulando-o à autonomia, ao exercício dos direitos e deveres, às habilidades com opção por atitudes mais saudáveis e ao controle das suas condições de saúde e qualidade de vida (BRASIL, 2011).

Considerando a importância da escola como espaço propício à formação de hábitos alimentares saudáveis e à construção da cidadania, foi publicada em 2006 a Portaria Interministerial $\mathrm{n}^{\mathrm{o}}$. 1010, que institui as diretrizes para a promoção da Alimentação Saudável nas escolas de Educação Infantil, Fundamental e nível Médio das redes públicas e privadas, em âmbito nacional. A Portaria tem como meta o desenvolvimento de ações que garantam a adoção de práticas alimentares mais saudáveis no ambiente escolar e avaliação de seu impacto a partir da análise de seus efeitos em curto, médio e longo prazo (BRASIL, 2006).
O consumo médio de frutas e hortaliças ainda é metade do valor recomendado pelo Guia Alimentar para a População Brasileira e manteve-se estável na última década (BRASIL, 2011). Um dos objetivos do Programa Nacional de Alimentação Escolar (PNAE) é aumentar a oferta e promover o consumo de frutas, legumes e verduras, com ênfase nos alimentos regionais.

Conceitualmente, perda ou desperdício é alguma mudança na viabilidade, comestibilidade, salubridade ou qualidade do alimento que o impeça de ser consumido por pessoas, podendo ser igual ao produto colhido menos o produto consumido (MARTINS e FARIAS, 2002).

Pesquisas mostram que são desperdiçados $30 \%$ dos alimentos comprados (cascas, talos, folhas e sementes de verduras, legumes e frutas) por falta de informação sobre o valor nutricional e forma correta de preparo (DAVID, 2007). Os resíduos de frutas e hortaliças são, geralmente, desprezados pela indústria e poderiam ser utilizados como fontes dos impactos ambientais (OLIVEIRA et al., 2002).

O Brasil está entre os dez países que mais desperdiçam alimentos no mundo. Paradoxalmente, 51 milhões de brasileiros vivem abaixo da linha da pobreza. O país produz 140 milhões de toneladas de alimentos por ano e é um dos maiores exportadores de alternativas de nutrientes, com o objetivo de 
aumentar o valor nutritivo da dieta bem como solucionar deficiências dietéticas do excesso alimentar (ESPÍNDOLA, 1987).

$\mathrm{O}$ aproveitamento de partes que normalmente são desprezadas, além de tornar a preparação de baixo custo, ser de fácil acesso e melhorar o valor nutricional, proporciona o aumento do rendimento da refeição (GAVA, 1984). Evitando o desperdício, é possível diminuir em até 30\% os gastos com alimentação. Além disso, aproveitar os alimentos ao máximo é uma maneira de colaborar para a diminuição efetiva do lixo orgânico, que hoje representa $65 \%$ de todo o lixo produzido no país (INSTITUTO AKATU, 2003).

Nos últimos anos, vários pesquisadores brasileiros vêm estudando o aproveitamento de resíduos, como as cascas de frutas, gerados pelas agroindústrias para a produção de alimentos ou ingredientes. Estas podem ser incluídas na dieta humana, como são os casos das cascas de maracujá, de laranja, de limão, de maçã e de outras frutas.

Assim a utilização econômica de resíduos de frutas oriundos do mercado in natura ou das agroindústrias, aliada ao desenvolvimento de tecnologias para minimizar as perdas nos processos produtivos, podem contribuir de forma significativa para a economia do país e a diminuição produtos agrícolas do mundo.

Ao mesmo tempo existem milhões de pessoas sem acesso ao alimento em quantidade e, ou qualidade (GONDIM et al., 2005). Segundo a EMBRAPA (2002) do total de desperdício no país, $10 \%$ ocorrem na colheita, $50 \%$ no manuseio e transporte, 30 $\%$ nas centrais de abastecimento, e os últimos $10 \%$ ficam diluídos entre supermercados e consumidores. Não há estudos conclusivos que determinem o desperdício em restaurantes, mas estima-se que as perdas nos setores de refeições coletivas cheguem a 15 $\%$.

O aproveitamento integral deve ser feito com técnicas culinárias adequadas a fim de melhorar o aporte de nutrientes nas refeições, de acordo com os princípios da alimentação saudável. Este trabalho teve como objetivo desenvolver receita de bolo de banana destinada à alimentação escolar, valorizando o aproveitamento integral de alimentos como forma de reduzir custo e agregar valor nutricional as preparações, além de diminuir impactos ambientais causados pelo lançamento de resíduos de alimentos ao meio ambiente.

\section{MATERIAL E MÉTODOS}

Amostras: Para a formulação dos bolos foi utilizada banana tipo nanica adquirida no comércio local da cidade de Alfenas, MG. As amostras foram transportadas para os laboratórios de Técnica Dietética e de Bromatologia da Universidade Federal de Alfenas, (Unifal-MG) onde foram 
processadas e incorporadas às preparações. A banana foi utilizada em sua forma integral. Foram utilizadas bananas com cascas íntegras e sem injúrias, que passaram por processo de limpeza que incluiu a lavagem sob água corrente potável empregando força mecânica, com uso de esponja.

Preparo das receitas: Todas as preparações foram desenvolvidas a partir de receitas pré- existentes de bolos simples, sendo elaborados dois tipos: uma contendo somente a polpa da fruta (B1) e a outra contendo a polpa e a casca (B2). Os outros ingredientes e suas quantidades foram mantidos sem variações para os dois bolos. Iniciou-se com o corte manual das bananas, depois foram processadas em liquidificador, sendo incorporados os seguintes ingredientes: leite integral, óleo de soja, ovos, açúcar refinado, farinha de rosca, farinha de trigo e fermento químico. As formulações encontram-se representadas na tabela 1 . Posteriormente a massa foi despejada numa fôrma, previamente untada com margarina e farinha de trigo. As preparações foram assadas em forno doméstico, por 40 minutos, em temperatura média de $180^{\circ} \mathrm{C}$.

\begin{tabular}{cccc}
\multicolumn{4}{l}{ Tabela 1- Formulação dos bolos } \\
\hline Ingrediente & B1 & B2 & Medida \\
\hline Banana & $300 \mathrm{~g}$ & $*$ & 3 unidades \\
Banana & $*$ & 279,6 & 3 unidades \\
Leite integral & $240 \mathrm{~mL}$ & $240 \mathrm{~mL}$ & 1 copo \\
Ovos & 1 unidade & 1 unidade & 1 unidade \\
Óleo de soja & $150 \mathrm{~mL}$ & $150 \mathrm{~mL}$ & 1 xícara
\end{tabular}

\begin{tabular}{cccc}
$\begin{array}{c}\text { Óleo de soja } \\
\text { Farinha de } \\
\text { Trigo }\end{array}$ & $\begin{array}{c}150 \mathrm{~mL} \\
100 \mathrm{~g}\end{array}$ & $\begin{array}{c}150 \mathrm{~mL} \\
100 \mathrm{~g}\end{array}$ & $\begin{array}{c}1 \text { xícara } \\
1 \text { xícara de } \\
\text { chá }\end{array}$ \\
$\begin{array}{c}\text { Farinha de } \\
\text { Rosca }\end{array}$ & $200 \mathrm{~g}$ & $200 \mathrm{~g}$ & $\begin{array}{c}2 \text { xícaras de } \\
\text { chá }\end{array}$ \\
$\begin{array}{c}\text { Açúcar } \\
\text { Refinado }\end{array}$ & $150 \mathrm{~g}$ & $150 \mathrm{~g}$ & $\begin{array}{c}1 \text { xícara de } \\
\text { chá }\end{array}$ \\
$\begin{array}{c}\text { Fermento } \\
\text { Químico }\end{array}$ & $10 \mathrm{~g}$ & $10 \mathrm{~g}$ & $\begin{array}{c}1 \text { colher de } \\
\text { sopa }\end{array}$ \\
\hline \multicolumn{2}{|c|}{ Fonte: Próprio autor } & &
\end{tabular}

Fonte: Próprio autor

Análises físico-químicas: Foi determinada a umidade, a textura, o teor de proteínas, carboidratos e lipídeos. Para a umidade, foi utilizada uma balança de secagem por radiação infravermelha da marca BEL Engineering®, que realiza a leitura direta do conteúdo de umidade por diferença de peso. A determinação de proteína foi realizada pelo método de Kjeldahl, no qual avaliou- se o teor de nitrogênio total de origem orgânica (AOAC, 1997). Para determinação de lipídeos foi utilizado o método de Bligh-Dyer (AOAC, 1997). A estimativa do teor de carboidratos ocorreu através da diferença dos valores encontrados do método de VAN SOEST (1991). Para a análise de firmeza, foi utilizado o texturômetro TA-XT2 Express (Stable Micro Systems, UK), segundo método AACC 4415A (AACC, 2000). Todas as análises físicoquímicas foram conduzidas em três repetições.

Análise sensorial: as duas amostras foram oferecidas para crianças de 9 a 11 anos, numa escola da rede pública do município de Alfenas - MG, utilizando-se a Escala Hedônica Facial (Figura 1), sendo oferecidas de forma aleatória. Após a degustação, cada 
criança marcava na escala hedônica a expressão facial que melhor representava a sua opinião em relação ao bolo provado. Esta foi interpretada por meio de porcentagem de escolhas da escala.

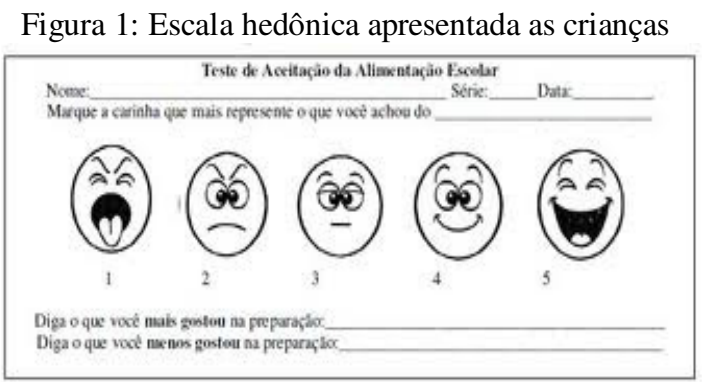

Fonte:Dutscosky, S.D (1996)

Análise estatística: Os resultados das análises físico-químicas foram interpretados por meio de análise de variância e os fatores qualitativos comparados utilizando ANOVA $(\mathrm{p} \leq 0,05)$.

\section{RESULTADOS E DISCUSSÃO}

Composição Química: Os dados referentes à composição físico-química dos bolos de banana estão apresentados na Tabela 2.

\begin{tabular}{lcc}
\multicolumn{3}{c}{ Tabela 2- Resultados das análises físico-químicas. } \\
\hline Análise & $\begin{array}{c}\text { Formulação } \\
\text { sem casca (B1) }\end{array}$ & $\begin{array}{c}\text { Formulação } \\
\text { com casca(B2) }\end{array}$ \\
\hline Proteína (\%) & $4,93 \mathrm{a}$ & $6,66 \mathrm{a}$ \\
Gordura (\%) & $20,02 \mathrm{a}$ & $19,26 \mathrm{a}$ \\
Umidade (\%) & $22,67 \mathrm{a}$ & $24,88 \mathrm{a}$ \\
Carboidratos & $52,38 \mathrm{a}$ & $49,2 \mathrm{a}$ \\
$*(\%)$ & & \\
\hline
\end{tabular}

\section{*Valores estimados por diferença} Médias acompanhadas de letras iguais, na mesma linha, não diferem entre si significativamente $(\mathrm{p} \leq 0,05)$.

Fonte: Próprio autor
Não foi observada diferença estatística significativa na composição centesimal dos dois tipos de bolos, o que sugere que independente da presença da casca da banana, o valor calórico e nutricional são semelhantes.

Observou-se conteúdo significativo de lipídeos nos dois bolos. Provavelmente esse fato está relacionado à adição da farinha de rosca derivada do processamento de pães. Cauvain (1987), afirma que a aeração proporcionada pela gordura é de fundamental importância no processo de produção de bolos. A estrutura é formada durante o estágio de batimento, quando bolhas de ar são incorporadas à massa. Essas bolhas crescem quando a temperatura aumenta formando a estrutura final porosa. A função de estabilização da massa é exercida pela fração cristalina da gordura.

Em bolos industrializados a umidade situa-se próximo a $30 \%$. Os valores obtidos neste trabalho para tal parâmetro estão adequados, sendo que a média de umidade obtida assemelha-se a de um bolo simples. A umidade em excesso aumenta a atividade microbiana e deixa as massas "grudentas", tornando o bolo mais susceptível ao esfacelamento (JOOSTE, 1951). Em estudo realizado por Rego et al. (2010), que analisou a composição centesimal de bolo com casca de banana prata, observou-se um teor de $48,60 \%$ de umidade, sendo que neste mesmo 
estudo, obteve-se $23,4 \%$ de umidade para um bolo simples.

Por motivos operacionais, não foi possível obter a determinação centesimal de fibras. Assim, realizou-se uma estimativa (Tabela 3) da sua composição em bolos de banana nanica com e sem a casca da fruta, tendo como base a Tabela Brasileira de Composição de Alimentos (UNICAMP, 2006).

Tabela 3- Suposição da composição de fibras do bolo de banana com casca e sem casca.

\begin{tabular}{lcc}
\hline & $\begin{array}{c}\text { Formulação sem } \\
\text { casca(B1) }\end{array}$ & $\begin{array}{c}\text { Formulação com } \\
\text { casca(B2) }\end{array}$ \\
\hline $\begin{array}{l}\text { Fibras } \\
\text { (g/100g bolo) }\end{array}$ & 1,63 & 1,83 \\
\hline \multicolumn{2}{c}{ Fonte: Tabela Brasileira de Composição de } \\
Alimentos - TACO (2006)
\end{tabular}

Com base nesta estimativa, sugere-se um maior teor de fibras em B2, sabendo que os resíduos não comestíveis das frutas como as cascas são ricas neste tipo de carboidrato. Segundo Gondim et al. (2005) a casca de banana apresenta quantidade de nutrientes maiores que sua parte comestível. O menor conteúdo de carboidratos em B2 pode estar relacionado à maior quantidade de fibras. Esta mesma relação também foi encontrado por Rego et al. (2010) .

Outro aspecto a ser levado em consideração é que o produto pode conter uma quantidade considerável de minerais devido ao enriquecimento com a casca da banana. Gondim et al. (2005) determinou a composição centesimal de cascas de frutas, concluindo que a casca da banana prata possui composição maior de elementos como o cálcio e o ferro.

O valor energético do bolo com a casca de banana foi de 389,46 Kcal, em uma porção de $100 \mathrm{~g}$. Comparado com outros bolos industrializados destinados ao público infantil, o produto desenvolvido na pesquisa apresenta maior quantidade de proteínas (Tabela 4).

Tabela 4- Valores energéticos de diferentes marcas de bolos - porção de $100 \mathrm{~g}$.

\begin{tabular}{cccc}
\hline & $\begin{array}{l}\text { Bolo com } \\
\text { casca de } \\
\text { banana }\end{array}$ & $\begin{array}{l}\text { Bolo } \\
\text { Panfi - } \\
\text { Panco }\end{array}$ & $\begin{array}{l}\text { Bolo } \\
\text { Bauducco- } \\
\text { Mesclado }\end{array}$ \\
\hline Valor energético & 389,46 & 398,3 & $435 \mathrm{Kcal}$ \\
Kcal & \\
Carboidratos & $47,31 \mathrm{~g}$ & $56,6 \mathrm{~g}$ & $51,7 \mathrm{~g}$ \\
Proteínas & $6,66 \mathrm{~g}$ & $5,5 \mathrm{~g}$ & $5 \mathrm{~g}$ \\
Lipídeos & $19,26 \mathrm{~g}$ & $16,7 \mathrm{~g}$ & $23,3 \mathrm{~g}$ \\
\hline \multicolumn{2}{c}{ Fonte: Próprio autor } & &
\end{tabular}

A dureza ou firmeza dos bolos de banana, avaliada por texturômetro é proporcional à força aplicada para morder (ESTELLER et al., 2004 apud ESTELLER et al., 2006). E a força máxima avaliada para os bolos, depende da sua formulação, umidade da massa e conservação (ESTELLER et al. 2006). O bolo com a casca de banana apresentou menor firmeza comparado ao bolo tradicional (Tabela 5). Esse fato pode ser explicado devido ao maior teor de umidade de B2, já que esta confere maior maciez à preparação. Souza et al. (2012), ao determinarem a textura de bolo contendo fubá, óleo e pasta de gergelim e amido 
resistente obtiveram resultado de $1,19 \mathrm{Kg} / \mathrm{f}$, enquanto para a fórmula padrão (bolo simples, com ingredientes básicos) foi de $1,29 \mathrm{Kg} / \mathrm{f}$.

Tabela 5- Valores estimados para a firmeza dos bolos. Formulação sem Formulação com casca (B1) casca (B2)

\begin{tabular}{lcc}
$\begin{array}{l}\text { Firmeza } \\
(\text { Kg/f) }\end{array}$ & $0,688 \pm 0,078$ & $0,435 \pm 0,048$ \\
\hline
\end{tabular}

*Resultados são médias de três determinações \pm desvio padrão.

Fonte: Próprio autor

$\mathrm{Na}$ Tabela 6 estão apresentados os resultados obtidos quanto ao rendimento e custo totais. Pode-se observar que o custo da preparação foi irrisório, principalmente quando é estimado o custo em uma porção de $60 \mathrm{~g}$, que foi de $\mathrm{R} \$ 0,17$. Comparado a outros bolos destinados ao público infantil que em média custam $\mathrm{R} \$ 1,05$ a porção $(60 \mathrm{~g})$, o bolo com a casca de banana seria uma opção para o lanche escolar, contribuindo para uma alimentação saudável e de baixo custo.

Tabela 6- Custo do produto desenvolvido - bolo de

\begin{tabular}{lcc}
\multicolumn{3}{c}{ banana com casca } \\
\hline \multicolumn{1}{c}{ Ingrediente } & Quantidade & RS \\
\hline Banana & $300 \mathrm{~g}$ & 0,477 \\
Farinha de Trigo & $100 \mathrm{~g}$ & 0,139 \\
& & \\
Farinha de & $200 \mathrm{~g}$ & 0,716 \\
Rosca & & \\
Açúcar & $150 \mathrm{~g}$ & 0,328 \\
Refinado & & \\
Leite & $240 \mathrm{~mL}$ & 0,453 \\
Ovo & $1 \mathrm{und}$ & 0,240 \\
Óleo & $150 \mathrm{~mL}$ & 0,158 \\
Fermento & $10 \mathrm{~g}$ & 0,199 \\
TOTAL & $970 \mathrm{~g}$ & 2,71 \\
\hline
\end{tabular}

Fonte: Próprio autor
A análise sensorial contou com participação de 40 crianças, na faixa etária de 9 a 11 anos. Para o bolo com casca de banana, foi observada a aceitabilidade entre $92,5 \%$ dos participantes (Gráfico 1), e em relação ao bolo sem a casca, a aceitabilidade foi de $98 \%$ (Gráfico 2), ou seja, os dois bolos apresentaram elevado grau de aceitabilidade. De acordo com Teixeira, Meinert e Barbetta (1987), para que um produto seja considerado aceito conforme suas propriedades sensoriais é necessário que atinja o índice mínimo de aceitabilidade de $70 \%$ da amostra, e segundo a PNAE o índice deve atingir pelo menos $85 \%$. Assim os bolos de banana apresentaram boa aceitabilidade, indicando que o produto não difere do tradicional quanto à aceitação pelo público infantil.

Gráfico 1. Aceitabilidade do bolo com a casca de banana entre as crianças participantes, Alfenas - MG.

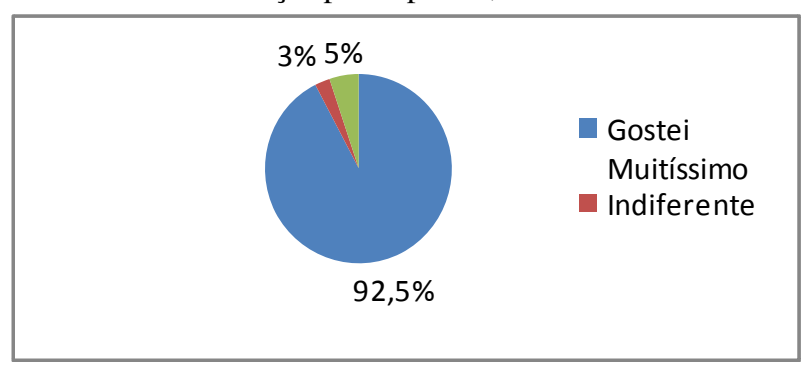

Fonte: Próprio autor

Gráfico 2. Aceitabilidade do bolo sem a casca da banana entre as crianças participantes, Alfenas - MG.

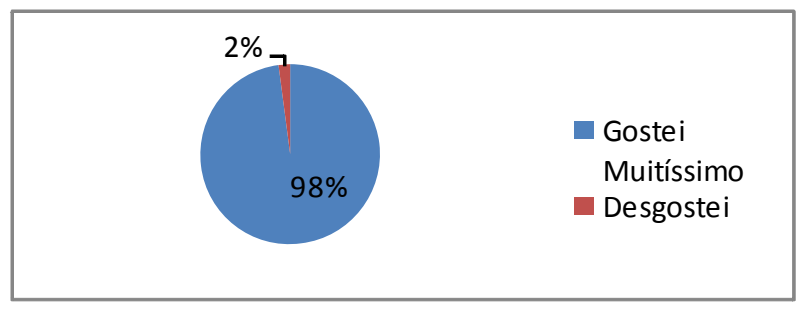

Fonte: Próprio autor 
Esta pesquisa contribuiu com a formulação de um produto de baixo custo, que promove o incentivo ao aproveitamento integral dos alimentos, sendo de fácil preparo e ainda melhora a qualidade nutricional do bolo. O produto pode ser uma opção para o lanche escolar, e também uma boa oportunidade para a realização de oficinas culinárias, que de acordo com a Resolução ${ }^{\circ}$ 38 do Fundo Nacional de Desenvolvimento da Educação (FNDE), são consideradas como estratégia de educação alimentar e nutricional.

\section{CONCLUSÃO}

A utilização de partes não comestíveis de alguns alimentos, como cascas provenientes de frutas na elaboração de produtos, como bolos, além de minimizar resíduos gerados e incorporar nutrientes às preparações, melhora a aceitabilidade dos produtos finais. Os resultados demonstram a importância do desenvolvimento de preparações alimentícias que utilizem o alimento de forma integral e sugere-se sua inclusão na alimentação escolar, de forma a contribuir ao acesso a uma alimentação saudável e ao mesmo tempo de baixo custo.

É necessária a conscientização da importância do aproveitamento integral de alimentos, não como uma prática destinada a população carente, mas como forma inteligente de se promover benefícios para toda sociedade.

\section{REFERÊNCIAS BIBLIOGRÁFICAS}

AACC - American Association of Cereal Chemists. Approved Methods of the American Association of Cereal Chemists, 10th ed., St. Paul 2000.

BRASIL - Ministério da Educação.

Resolução/CD/FNDE n ${ }^{\circ} 38$. Dispõe sobre o atendimento da alimentação escolar aos alunos da educação básica no Programa Nacional de Alimentação Escolar - PNAE. Brasília: Ministério da Educação, 2009.

\section{BRASIL. Política Nacional de Alimentação}

e Nutrição. Disponível em $<$ http://189.28.128.100/nutricao/docs/geral/pn an2011.pdf $>$ acesso em 10 fev. 2013.

\section{BRASIL. Portaria Interministerial No-} 1.010, de 8 de maio de 2006. Ministério da Educação, 2006.

BRASIL. Promoção da Alimentação Saudável no ambiente escolar. Política Nacional de Alimentação e Nutrição, 2011. Disponível em:

http://nutricao.saude.gov.br/pas.php?conteudo =promocao_ambiente_escolar $>$ acesso em 10 fev. 2013. 
CAUVAIN, S. Let them eat cake especially if it's low fat. Food FlavIngredPackag

Process, v. 9, n. 8, p. 37-39, 1987.

EMBRAPA. Desperdício de Alimentos no

Brasil - um desafio político e social a ser

vencido. Ministério da Agricultura, Pecuária

e Abastecimento, 2002.

ESPÍNDOLA, F. S. Fracionamento dos

vegetais verdes e obtenção de concentrados

protéicos de folhas (CPF) para

suplementação de alimentos e ração

animal, com aproveitamento dos

subprodutos. 1987. 140 f. Monografia

(Graduação em Agronomia) - Universidade

Federal de Uberlândia, Uberlândia.

ESTELLER, M. S. et al. Bolo de "chocolate" produzido com pó de cupuaçu e kefir. Rev.

Bras. Cienc. Farm., São Paulo, v. 42, n. 3, jul./set., 2006.

GAVA, A. J. Princípio de Tecnologia de

Alimentos. São Paulo. Nobel, 1984.

GONDIN, J. A.M. et al., Composição

Centesimal e de Minerais em Casca de Frutas.

Revista de Ciência e Tecnologia de

Alimentos .São Paulo. V.25, n.4, p.825-827, out/dez , 2005.
GOULART, R.M. Desperdício de alimentos: Um problema de saúde pública. JUL./AGO./SET. 2008. ANO XIV, $\mathrm{N}^{\circ}$ 54. 285-288.

INSTITUTO AKATU. Maioria das pessoas não aproveita integralmente os alimentos. 2003. Disponível em:<http://www.akatu.org.br/Temas/Aliment os/Posts/Maioria-das-pessoas-nao-aproveitaintegralmente-os-alimentos. >Acesso em: 30 de Maio 2012.

MARTINS, R. C.; FARIAS, R. M., Produção de alimentos x desperdício: tipos, causas e como reduzir perdas na produção agrícola.

Revista da Faculdade de Zootecnia, Veterinária e Agronomia, Uruguaiana, 9(1): 20-32, 2002.

OLIVEIRA, L.F. et al. Aproveitamento alternativo da casca do maracujá-amarelo (Passiflora edulis f. flavicarpa) para produção de doce em calda. Rev. Ciência e Tecnologia de Alimentos, Campinas, v.33, n.3, p.259262, 2002. Disponível em: $<$ www.scielo.com.br>. Acesso em 24.09.2009.

REGO, F. F. A. et al. Análise da Composição centesimal do bolo da casca de Banana Prata. 
In: CONGRESSO BRASILEIRO DE

QUÍMICA, 50, 2010, Cuiabá. Anais...Rio de

Janeiro: Associação Brasileira de Química,

2010.

SOUZA, E.P. et al. Bolo contendo fubá, óleo

e pasta de gergelim e amido resistente:

características sensoriais e technológicas.

RevistaAgrotecnologia, Anápolis, v. 3, n. 2,

p. $108-124,2012$.

TEIXEIRA, E.; MEINERT, E.; BARBETTA,

P. A. Análise sensorial dos alimentos.

Florianópolis: Ed. Da UFSC, 1987.

UNICAMP. Tabela Brasileira de

Composição de Alimentos -TACO -

Versão II, 2. Ed., Campinas, SP: NEPA-

UNICAMP, 2006.

VAN SOEST, P. J., ROBERTSON, J.B.,

LEWIS, B.A. Methods for dietary fiber,

neutrldetergent fiber, and nonstarch

polysaccharides in relation to animal

nutrition. Jounal of Dairy Science. V.74,

n.10, p.3583-3597, 1991. 